\title{
Kajian Kualitas Beberapa Pupuk Kompos Produksi Simantri di Daerah Bali Sesuai dengan Standar Nasional Indonesia Tahun 2004 (SNI 19-7030-2004)
}

\author{
A.A. NYOMAN SUPADMA*), I MADE MEGA, DAN I MADE DANA \\ Program Studi Agroekoteknologi Fakultas Pertanian Universitas Udayana \\ Jl. PB. Sudirman Denpasar 80362 Bali \\ ${ }^{*}$ E-mail: supadmaagung@gmail.com
}

\begin{abstract}
Study of the Quality of Some Compost Fertilizer Simantri Production in Bali in Accordance with Indonesian National Standard-2004 (SNI 19-70302004). In Bali currently has circulated various types of compost, but testing of the quality most have not done regularly. Efforts to protect the consumer need to be implemented through the compost quality testing in the laboratory. This is done to prevent counterfeiting and ensure the quality of the compost is already in line with the quality standard SNI-2004. Among compost circulating in Bali, is compost Gapoktan Simantri production. The purpose of this study is to determine some of the physical and chemical properties of some Simantri's compost circulating in Bali, whether in accordance with the criteria of the quality of compost SNI 19-7030-2004. Compost quality standards SNI-2004 are water content $(<50 \%), \mathrm{pH}(6.8$ to 7.49$)$, total-N (> 0.4\%), C-organic (9.80 to 32\%), P2O5 (>0.10\%), K2O (>0.20\%), C / N ratio (10-20), organic matter (27-58\%), smells like soil, blackish color, and the temperature not hot. Compost sampling method for testing a composite on Gapoktan Simantri in Bali as many as 20 samples of compost. Parameters include: water content (grafimetri), $\mathrm{pH}$ (electrode glas), total-N (method of Kjeldhal), $\mathrm{P}_{2} \mathrm{O}_{5}$ and $\mathrm{K}_{2} \mathrm{O}$ (method of extracting HCL 25\%), organic $\mathrm{C}$ (method of Walkley and Black), material organic, EC (coductometer), $\mathrm{C} / \mathrm{N}$ ratio, color, temperature, and smell of the compost. Data obtained from the analysis in laboratory are compared to standard quality of compost according to SNI 19-7030-2004. The results showed that the total-N of compost Simantri is very high (1.13 to $2.11 \%), \mathrm{P}$ content is very high ( 0.103 to $0.123 \%)$, $\mathrm{K}$ content is very high $(0.902$ to $2.342 \%)$, C-organic is very high (14.08 to $25.48 \%), \mathrm{C} / \mathrm{N}$ ratio (10.52 to 18.52$)$, organic matter (24.87 to $43.93 \%)$ (all of these parameters in accordance with SNI-2004) ; pH (6.65 to 8.36) (some not suitable SNI-2004), EC (2.31 to $8.46 \mathrm{mmhos} / \mathrm{cm}^{2}$ ) (some very high), moisture content (36.60 to $56.60 \%$ ) (some not suitable SNI-2004), blackish color, smells like soil, and temperature not hot (according to the standard SNI-2004). The majority (57.14\%) of compost Simantri examined in accordance with the standard quality compost SNI-2004, but (42.86\%) is not in accordance (pH and water content of compost).
\end{abstract}

Keywords: quality compost, Simantri, SNI-2004 


\section{A.A. NYOMAN SUPADMA. et al. Kajian Kualitas Beberapa Pupuk Kompos Produksi Simantri...}

\section{PENDAHULUAN}

Keberhasilan produksi pertanian melalui kegiatan intensifikasi tidak terlepas dari kontribusi dan peranan sarana produksi, antara lain pupuk yang merupakan salah satu faktor penentu produksi pertanian. Selama ini untuk mendukung pembangunan sektor pertanian, khususnya subsektor tanaman pangan dan hortikultura, pemerintah menyediakan dana untuk subsidi pupuk buatan (Urea, SP-36, ZA dan $\mathrm{KCl}$ ) (Suriadikarta dkk., 2006).

Namun belakangan ini pupuk organik (pupuk kompos) mulai banyak digunakan di lahan pertanian untuk meningkatkan kesuburan tanah (Sugito dkk., 2005 dan Syekhfani, 2005). Oleh karena itu untuk menjamin kualitas pupuk organik, perlu adanya pengawasan atau pengaturan persyaratan kualitas pupuk organik (Simanungkalit dkk., 2006). Apabila kompos diproduksi dan diedarkan secara luas untuk dijual secara komersial, maka diperlukan pengawasan atau suatu regulasi agar kompos yang diperjualbelikan tersebut memenuhi persyaratan standar kualitas yang baik.

\section{Menurut}

Permentan

No.2/Pert/Hk.060/2/2006, tentang pupuk organik dan pembenah tanah, dikemukakan bahwa pupuk organik adalah pupuk yang sebagian besar atau seluruhnya terdiri atas bahan organik yang berasal dari tanaman dan atau hewan yang telah melalui proses rekayasa, dapat berbentuk padat atau cair yang digunakan mensuplai bahan organik untuk memperbaiki sifat fisik, kimia, dan biologi tanah. Definisi tersebut menunjukkan bahwa pupuk organik lebih ditujukan kepada kandungan C-organik, dibandingkan dengan kadar haranya, dan nilai C-organik itulah yang menjadi pembeda dengan pupuk anorganik (Simanungkalit dkk., 2006).

Di pasaran saat ini telah beredar berbagai jenis pupuk kompos baru hasil rekayasa teknologi, termasuk pupuk kompos produksi Simantri di Bali, namun pengujian kualitasnya belum dilakukan secara berkala. Untuk itu maka pengguna perlu berhati-hati dalam memilih jenis kompos maupun pupuk organik yang akan digunakan agar dapat meningkatkan hasil dan memperbaiki kualitas tanah. Beberapa pupuk produksi Simantri telah mencantumkan kandungannya pada lebel kemasan, namun belum tentu kandungan haranya tersebut memenuhi standar kualitas kompos SNI-2004. Indonesia telah memiliki standar kualitas kompos, yaitu SNI 19-7030-2004 dan Peraturan Menteri Pertanian No. 02/Pert/HK.060/2/2006. Di dalam standar ini termuat batas-batas maksimum atau minimum sifat-sifat fisik atau kimiawi kompos, termasuk di dalamnya batas maksimum kandungan logam berat. Standar kualitas kompos menurut SNI (2004) antara lain : Kadar air (<50\%), pH (6,8 $7,49)$, kadar $\mathrm{N}(>0,4 \%), \mathrm{C}(9,80-32 \%)$, $\mathrm{P} 2 \mathrm{O} 5(>0,10 \%), \mathrm{K} 2 \mathrm{O}(>0,20 \%), \mathrm{C} / \mathrm{N}$ rasio (10-20), bahan organik $(27-58 \%), \mathrm{Ca}$ $(<25,5 \%), \mathrm{Mg}(<0,6 \%), \mathrm{Fe}(<2 \%), \mathrm{Al} \quad(<2,2$ $\%)$, dan Mn $(0,1 \%)$. Sifat fisik yang lain : warna coklat kehitaman, berbau seperti tanah, dan suhunya tidak panas.

Menurut Tantri dkk. (2016) bahwa hasil pengujian 10 jenis pupuk kompos yang diperdagangkan di Denpasar, ternyata hanya 2 jenis kompos yang kualitasnya sudah sesuai dengan standar SNI-2004, yaitu kompos Bio-Extrim Trubus dan kompos Putri Liman Simantri 096 Blahbatuh 
Gianyar. Dengan demikian perlindungan terhadap petani perlu dilaksanakan melalui pengujian kualitas pupuk kompos produksi Simantri yang telah diperdagangkan di daerah Bali secara rutin melalui uji laboratorium. Hal ini dilakukan untuk menghindari terjadinya pemalsuan pupuk serta menjamin kualitas pupuk agar sesuai dengan standar SNI-2004. Menurut Isroi dan Yuliarti (2009) bahwa kompos yang baik adalah kompos yang siap untuk diaplikasikan dan tidak berbahaya bagi tanaman, manusia, dan lingkungan. Jaminan terhadap kepastian kualitas pupuk kompos untuk meningkatkan produksi tanaman perlu dilakukan secara terus menerus, karena selain untuk melindungi konsumen juga untuk menggalang kepercayaan petani terhadap penggunaan pupuk komposguna meningkatkan kualitas dan produksi pertanian secara berkelanjutan

Berdasarkan permasalahan yang diuraikan di atas, maka dilakukan kajian terhadap kualitas pupuk kompos produksi Simantri yang sudah banyak diperdagangkan di daerah Bali, apakah kualitas fisik maupun kimia kompos tersebut telah memenuhi kriteria standar SNI 19-7030-2004.

Tujuan penelitian ini antara lain: untuk mengetahui kualitas fisik dan kimia pupuk kompos produksi Simantri yang telah beredar dan diperdagangkan di daerah Bali. Hasil penemuan penelitian ini dapat disarankan kepada pemerintah daerah Bali untuk bahan acuan dalam pembinaan kepada Gapoktan (Gabungan Kelompok Tani) Simantri di daerah Bali guna dapat secara bertahap meningkatkan kualitas kompos produksi Simantri agar nantinya sesuai dengan standar aturan SNI-2004.

\section{METODE PENELITIAN}

Penelitian ini di laksanakan mulai bulan Juli sampai Oktober 2016 mulai dari persiapan, pengambilan sampel pupuk kompos Simantri yang beredar di Bali, kemudian dilakukan analisiskadar unsur hara di Laboratorium Ilmu Tanah dan Lingkungan, Fakultas Pertanian Universitas Udayana. Bahan yang digunakan pada penelitian ini adalah jenis sampel pupuk kompos produk Simantri yang diperdagangkan di Bali, masing-masing diambil 1-3 sampel. sehingga jumlahnya menjadi 20 sampel kompos Simantri. Bahan yang lainnya seperti aquadest, dan zat-zat kimia untuk analisis di laboratorium. Alatalat yang digunakan pada penelitian ini yaitu alat timbangan elektrik, saringan, oven, tabung reaksi, pipet, $\mathrm{pH}$ meter, mesin pengocok, beaker glass, alat titrasi, labu kjedhal, alat destruksi, spektrofotometer, flamefotometer, dan konduktometer.

Pengambilan sampel pupuk kompos produksi Simantri, dilakukan dengan mengambil pupuk kompos yang telah diperdagangkan di Bali dan juga pada Gapoktan Simantri. Penentuan sampel dapat dilakukan dengan menggunakan metode random sampling, yaitu diambil secara acak di masing-masing kabupaten dan kota di Bali sebanyak 1 - 3 sampel, sehingga jumlah sampel kompos Simantri menjadi 20 sampel. Lokasi pengambilan contoh kompos dilakukan di produsen, agen, toko, dan kios sarana pertanian pada tingkat desa, kecamatan, dan kota/ kabupaten di daerah Bali (Tabel 1). Kabupaten tempat pengambilan sampel sebagai berikut: Kabupaten Tabanan, Jembrana, Gianyar, 


\section{A.A. NYOMAN SUPADMA. et al. Kajian Kualitas Beberapa Pupuk Kompos Produksi Simantri...}

Badung, Bangli, Klungkung, Karangasem, dan Buleleng.

Berat sampel pupuk kompos yang diambil masing- masing 10-20 kg untuk dianalisis di laboratorium Tanah Fakultas Pertanian Universitas Udayana, dan Laboratorium Analitik Universitas Udayana. Parameter yang diamati kualitas fisik dan kimia pupuk kompos, sebagai berikut : $\mathrm{pH}$ $\left(\mathrm{H}_{2} \mathrm{O}\right)$ ( $\mathrm{pH}$ meter); Daya Hantar Listrik (DHL) $\mathrm{H}_{2} \mathrm{O}$ 1:2,5 (Konduktometer); Kadar C-organik (metode Walkley and Black); Kadar N-total (metode Kjeldhal); P-total (metode ekstrak $\mathrm{HCl} \quad 25 \quad \%$ )
(Spektrofotometer); K- total (metode ekstrak $\mathrm{HCl} 25 \%$ ) (Flamefotometer); $\mathrm{C} / \mathrm{N}$ rasio; Kadar air kompos (Gravimetri): Warna kompos: Bau kompos: dan suhu kompos.

Data yang diperoleh dari hasil analisis kompos di laboratorium dibandingkan secara deskriptif dengan standar mutu kualitas kompos SNI-2004; dan disajikan dalam Tabel 1 dan Tabel 2.

\section{HASIL DAN PEMBAHASAN}

Hasil analisis laboratorium sifat kimia dan fisika kompos Simantri disajikan pada Tabel 1 dan Tabel 2.

Tabel 1. Kandungan hara N, P, K, C-organik dan C/N rasio kompos Simantri

\begin{tabular}{lrrrrr}
\hline No. $\quad$ Jenis Kompos & $\begin{array}{r}\text { N-total } \\
(\boldsymbol{\%})\end{array}$ & $\begin{array}{r}\text { P-total } \\
(\mathbf{\%})\end{array}$ & $\begin{array}{r}\text { K-total } \\
(\boldsymbol{\%})\end{array}$ & $\begin{array}{r}\text { C-organik } \\
(\boldsymbol{\%})\end{array}$ & C/N rasio \\
\hline 1. Simatri Tegalinggah, Tabanan & 1,66 & 0,103 & 0,902 & 23,97 & 14,44 \\
2. Simantri Selanbawak Tabanan & 1,59 & 0,109 & 2,089 & 23,72 & 14,91 \\
3. Simantri Kukuh Marga Tabanan & 1,39 & 0,111 & 1,615 & 20,67 & 14,87 \\
4. Simantri Kelating, Tabanan & 1.13 & 0.361 & 0.580 & 19.87 & 17.58 \\
5. Bintang Tani Marga - Tabanan & 1.14 & 0.328 & 0.961 & 8.56 & 16.28 \\
6. Simantri Pejeng Klod Gianyar & 1,75 & 0,123 & 2,132 & 25,48 & 14,56 \\
7. Simantri Guang Gianyar & 1,38 & 0,117 & 0,848 & 23,64 & 17,13 \\
8. Simantri Tegalalang Gianyar & 1,39 & 0,110 & 1,149 & 20,23 & 15,09 \\
9. Agung Super Ds Singapadu, Gianyar & 1.15 & 0.403 & 0.324 & 18,27 & 15.88 \\
10. Simantri Putri Liman Blahbatuh & 1.28 & 0.410 & 0.769 & 18.07 & 14.12 \\
11. Simantri Desa Pikat Dawan Klungkung & 1,36 & 0,156 & 2,143 & 17,23 & 12,67 \\
12. Simantri Desa Takmung Klungkung & 1,36 & 0,226 & 1,347 & 17,25 & 12,68 \\
13. Simatri Budakeling, Karangasem & 1,36 & 0,106 & 2,133 & 17,68 & 13,00 \\
14. Simantri Sidemen Karangasem & 1,00 & 0.110 & 0,987 & 14,08 & 14,08 \\
15. Simantri Duda Selat Karangasem & 2,11 & 0,110 & 2,342 & 22,20 & 10,57 \\
16. Simantri Dangin Tukadaya Jembrana & 1,09 & 0,115 & 0,484 & 20.19 & 18,56 \\
17. Simantri Yehembang Jembrana & 1,53 & 0,107 & 0,920 & 20,80 & 13,59 \\
18. Simantri Desa Abuan Kintamani Bangli 1,37 & 0,112 & 1,293 & 19,88 & 14,52 \\
19. Simantri Sangeh Badung & 1,35 & 0,242 & 1,231 & 17,65 & 13,07 \\
20. Simantri Desa Lokapaksa Buleleng & 1,33 & 0,281 & 1,733 & 18,11 & 13,62 \\
\hline 21. Standar SNI-2004 & $>\mathbf{0 . 4 0}$ & $>\mathbf{0 . 1 0}$ & $>\mathbf{0 . 2 0}$ & $>\mathbf{9 , 8 - 3 2}$ & $\mathbf{1 0 - 2 0}$ \\
\hline sda & & & & & \\
& & & & & \\
\hline
\end{tabular}


Hasil penelitian menunjukkan bahwa kadar $\mathrm{N}$ total semua kompos tergolong sangat tinggi $(0,86-2,11 \%)$ (sesuai SNI2004), kadar $P$ tergolong sangat tinggi $(0,103$ - 0,123 \%) (sesuai SNI-2004), kadar K tergolong sangat tinggi $(0,902-2,342 \%)$ (sesuai SNI-2004), kadar C-organik sangat tinggi $(14,08-25,48 \%)$ (sesuai SNI-2004), $\mathrm{C} / \mathrm{N}$ rasio $(10,57$ - 18,56) (sesuai SNI-2004), kadar Bahan organic $(24,87$ - 43,93 \%) (sesuai SNI-2004), pH berkisar $(6,65-8,36)$ (beberapa tidak sesuai SNI-2004), DHL (2,31 $-8,46 \mathrm{mmhos} / \mathrm{cm}^{2}$ ) (beberapa sangat tinggi), Kadar air (36,60 - 56,60 \%) (beberapa tidak sesuai SNI-2004), warna kehitaman, suhu tidak panas atau normal dan berbau seperti tanah (sesuai standar SNI-2004) (Tabel 1 dan Tabel 2)

Kadar N, P dan $\mathrm{K}$ total kompos, semuanya telah memenuhi persyaratan SNI2004, kadar C-organik dan kadar bahan organic kompos juga semuanya telah memenuhi persyaratan SNI-2004. Untuk mengetahui tingkat kematangan kompos dilihat dari $\mathrm{C} / \mathrm{N}$ rasio, dan semua kompos telah memenuhi persyaratan SNI-2004. Pada Tabel 2 nampak bahwa beberapa kompos Simantri ada yang belum memenuhi persyaratan SNI-2004, yakni pH lebih rendah dari persyaratan SNI- 2004 antara lain kompos Simantri Kukuh Marga Tabanan $(\mathrm{pH}$ 6,73), dan kompos Simantri Guang Gianyar (pH 6,65). Hal ini kemungkinan disebabkan karena kompos tersebut telah menghasilkan asam-asam organic seperti asam humat, fulvat, dan humin sehingga menyebabkan $\mathrm{pH}$ sedikit turun, namun masih tergolong netral (Tan, 1991). Pupuk kompos Simantri Tegalinggah dan Selanbawak Tabanan, demikian pula kompos Simantri Pejeng Klod Gianyar, Kompos Simantri Sidemen Karangasem, Duda Selat Karangasem, serta kompos Simantri Yehembang Jemberana $\mathrm{pH}$ nya melebihi persyaratan SNI-2004. Hal ini kemungkinan karena kelebihan dalam penambahan bahan dolomit atau kapur yang digunakan dalam proses pengomposan, yang mana dolomit atau kapur banyak mengandung basa-basa seperti $\mathrm{Ca}$ dan $\mathrm{Mg}$ sehingga dapat meningkatkan $\mathrm{pH}$ kompos.

Untuk persyaratan warna, suhu, dan bau kompos, hampir semua kompos Simantri telah memenuhi persyaratan warna kehitaman, tidak panas, berbau seperti tana, kecuali Simantri Yehembang Jembrana. Kompos tersebut tekstur dan baunya masih seperti kotoram kambing, disebabkan karena bahannya sebagian besar kotoran kambing yang sulit melapuk. Mengenai persyaratan kadar air kompos, hanya kompos Simantri Tegalinggah Tabanan yang melebihi persyaratan SNI-2004 yaitu kadar airnya mencapai 56,60 \% (Tabel 2), hal ini kemungkinan disebabkan kompos yang dihasilkan kurang dideder (dianginkan) sehingga masih mengandung kadar air yang melebihi persyaratan SNI-2004. 


\section{A.A. NYOMAN SUPADMA. et al. Kajian Kualitas Beberapa Pupuk Kompos Produksi Simantri...}

Tabel 2. Kandungan bahan organic, pH, DHL, warna,bau dan suhu kompos Simantri

\begin{tabular}{|c|c|c|c|c|c|}
\hline Jenis Kompos & $\begin{array}{c}\text { Bahan organic } \\
(\%)\end{array}$ & pH & $\begin{array}{c}\text { DHL } \\
\text { (mmhos) }\end{array}$ & $\begin{array}{c}\text { Kadar Air } \\
(\%)\end{array}$ & $\begin{array}{r}\text { Warna/ } \\
\text { bau/suhu }\end{array}$ \\
\hline 1. Simatri Tegalinggah,Tabanan*) & 41,33 & 7,89 ts & 8,46 & 56,60 ts & $\mathrm{khm} / \mathrm{t} / \mathrm{n}$ \\
\hline 3. Simantri Selanbawak Tabanan*) & 40,89 & 7,85 ts & 3,42 & 44,17 & $\mathrm{khm} / \mathrm{t} / \mathrm{n}$ \\
\hline 11. Simantri Kukuh Marga Tabanan*) & 35,63 & 6,73 ts & 3,64 & 37,79 & $\mathrm{khm} / \mathrm{t} / \mathrm{n}$ \\
\hline 12. Simantri Kelating,Tabanan & 34,26 & 7,24 & 3,65 & 26.24 & $\mathrm{khm} / \mathrm{t} / \mathrm{n}$ \\
\hline 15. Bintang Tani Marga - Tabanan & 32,0 & 7,20 & 3,23 & 25,21 & $\mathrm{khm} / \mathrm{t} / \mathrm{n}$ \\
\hline 4. Simantri Pejeng Klod Gianyar*) & 43,93 & 8,36 ts & 2,41 & 43,10 & $\mathrm{khm} / \mathrm{t} / \mathrm{n}$ \\
\hline 9. Simantri Guang Gianyar*) & 40,75 & 6,65 ts & 2,31 & 54,81 & tskhm/t/n \\
\hline 14. Agung Super Ds Singapadu, Gianyar & 31,50 & 7,12 & 2,10 & 24,67 & $\mathrm{khm} / \mathrm{t} / \mathrm{n}$ \\
\hline 10. Simantri Tegalalang Gianyar & 35,05 & 7,28 & 5,38 & 45,80 & $\mathrm{khm} / \mathrm{t} / \mathrm{n}$ \\
\hline 18. Simantri Putri Liman Blahbatuh & 31,15 & 7,08 & 3,12 & 20,43 & $\mathrm{khm} / \mathrm{t} / \mathrm{n}$ \\
\hline 16. Simantri DsPikat Dawan Klungkung & 29,71 & 6,98 & 2,76 & 22,47 & $\mathrm{khm} / \mathrm{t} / \mathrm{n}$ \\
\hline 19. Simantri Desa Takmung Klungkung & 29,74 & 7,23 & 3,02 & 21,23 & $\mathrm{khm} / \mathrm{t} / \mathrm{n}$ \\
\hline 2. Simatri Budakeling, Karangasem*) & 30,48 & $7,88 \mathbf{t s}$ & 3,61 & 33,47 & $\mathrm{hm} / \mathrm{t} / \mathrm{n}$ \\
\hline 5. Simantri Sidemen Karangasem*) & 24,27 & 7,68 ts & 2,55 & 31,16 & $\mathrm{khm} / \mathrm{t} / \mathrm{n}$ \\
\hline 8. Simantri Duda Selat Karangasem*) & 38,27 & 7,86 ts & 3,71 & 42,60 & $\mathrm{khm} / \mathrm{t} / \mathrm{n}$ \\
\hline 6. Simantri Dangin Tukadaya Jembrana & 34,81 & 7,10 & 2,83 & 40,67 & $\mathrm{khm} / \mathrm{t} / \mathrm{n}$ \\
\hline 7. Simantri Yehembang Jembrana*) & 25,86 & 8,36 ts & 6,65 & 38,62 & $\mathrm{khm} / \mathrm{t} / \mathrm{n}$ \\
\hline 13. Simantri Ds Abuan Kintamani Bangli & 34,27 & 7,41 & 3,12 & 30,76 & $\mathrm{khm} / \mathrm{t} / \mathrm{n}$ \\
\hline 17. Simantri Sangeh Badung & 30,43 & 7,31 & 3,84 & 23,86 & $\mathrm{khm} / \mathrm{t} / \mathrm{n}$ \\
\hline 20. Simantri Desa Lokapaksa Buleleng & 31,22 & 7,41 & 3,77 & 27,35 & $\mathrm{khm} / \mathrm{t} / \mathrm{n}$ \\
\hline 21. Standar SNI-2004 & $27-58$ & $6,8-7,4$ & & & \\
\hline
\end{tabular}

Keterangan : $\mathbf{t s}=$ tidak sesuai dengan SNI-2004. *) = Jenis kompos yang tidak sesuai dengan SNI-2004. $\mathbf{k h m}=$ warna kehitaman. $\quad \mathbf{t}=$ bau seperti tanah. $\quad \mathbf{n}=$ suhu normal

Dalam pembuatan kompos, bahan baku pupuk kompos sangat mempengaruhi kualitas pupuk kompos yang dihasilkan. Salah satu bahan baku pupuk kompos yang baik yaitu kotoran sapi dan kambing sebesar $90 \%$, bahan organik (tepung darah dan isi rumen kambing, arang sekam, sekam alas kandang ayam, abu, daun-daunan, dedak), dan dolomite serta mikroba $10 \%$ (mikroba pengikat $\mathrm{N}$ dan pengurai $\mathrm{P}$ ) (Anon., 2014). Kandungan nitrogen pupuk kompos yang diteliti semuanya sangat tinggi, hal ini disebabkan karena bahan baku pupuk kompos Simantri mengandung hampir $90 \%$ kotoran sapi atau kambing. Selain itu semua pupuk kompos termasuk sudah matang (terdekomposisi sempurna) dilihat dari $\mathrm{C} / \mathrm{N}$ rasio kompos < 20, kompos berwarna kehitaman dan telah berbau seperti tanah (Outerbridge, 1991). Murbandono (2009) menyatakan bahwa kompos yang baik adalah kompos yang memiliki $\mathrm{C} / \mathrm{N}$ rasio $10-12$, sedangkan Novizan (2005) menyatakan bahwa kompos yang baik adalah yang mengandung $\mathrm{C} / \mathrm{N}$ rasio $12-15$. Rasio $\mathrm{C} / \mathrm{N}$ akan mempengaruhi ketersediaan unsur hara, jika $\mathrm{C} / \mathrm{N}$ rasio tinggi maka kandungan unsur hara sedikit tersedia untuk tanaman, 
sebaliknya jika $\mathrm{C} / \mathrm{N}$ rasio rendah maka ketersediaan unsur hara tinggi dan sangat tersedia bagi tanaman.

Kandungan unsur hara phosfor (P-total) yaitu semua tergolong sangat tinggi, demikian pula kandungan K-total semua sangat tinggi. Berdasarkan nilai kadar P dan Kdari pupuk kompos Simantri yang dihasilkan semuanya sudah memenuhi syarat SNI-2004 yaitu >0,10 \% (untuk P) dan > $0,20 \%$ (untuk K). Menurut Stofella dan Khan (2001) bahwa unsur $P$ sangat diperlukan oleh mikroorganisme perombak untuk membangun selnya seperti protoplasma dan inti sel. Perombakan bahan organik dan proses asimilasi fosfor terjadi karena adanya enzim fosfatase yang dihasilkan oleh sebagian mikroorganisme. Apabila jumlah mikroorganisme dalam pengomposan kurang maka proses perombakan bahan organik dan proses asimilasi fosfor oleh mikroorganisme juga kurang, sehingga fosfor kurang termanfaatkan, sebaliknya jika jumlah mikroorganisme dalam komposan cukup maka proses perombakan bahan organik berjalan sempurna. Demikian juga halnya dengan kandungan $\mathrm{K}$ dalam bahan kompos, Sutedjo (1996) menyatakan bahwa kalium digunakan oleh mikroorganisme dalam bahan komposan sebagai katalisator, dengan kehadiran bakteri dan aktivitasnya, sangat berpengaruh terhadap peningkatan kandungan kalium. Kalium diikat dan disimpan dalam sel oleh bakteri dan jamur, jika dekomposisi kembali maka kalium akan menjadi tersedia kembali bagi tanaman.

Berdasarkan hasil analisis kandungan C-organik kompos, kandungan C-organik pupuk kompos Simantri berkisar dari tinggi sampai sangat tinggi. Total C-organik dalam pupuk dipengaruhi oleh kualitas bahan kompos dan aktifitas mikroorganisme yang terlibat dalam penguraian bahan organic. Kandungan bahan organik dari hasil pupuk kompos Simantri semuanya telah sesuai dengan persyaratan SNI-2004, karena bahan dasarnya kotoran ternak sapi dan sisa-sisa tanaman.

Pupuk kompos Simantri Tegallinggah, Tabanan, dan Guang Gianyar mempunyai kadar air yang melebihi standar SNI-2004, yaitu mengandung kadar air 56,60\% dan $54,81 \%$ lebih tinggi dari $>50 \%$. Tingginya kadar air kompos akan berakibat bahan semakin padat, karena dapat melumerkan sumber makanan yang dibutuhkan mikroba dan memblokir oksigen untuk masuk ke dalam kompos. Kondisi tersebut dapat menyebabkan suasana menjadi anaerob, sehingga mikroba yang ada dalam kompos kemungkinan banyak yang akan mati (Isroi dan Yuliarti, 2009). Sifat fisik pupuk kompos Simantri yang lain: warna, bau dan suhu semua sudah memenuhi standar SNI-2004 yaitu suhu normal, warna dari coklat sampai kehitaman, dan berbau tanah. Indikator tersebut sudah menunjukkan kematangan kompos yang dihasilkan.

\section{SIMPULAN}

Berdasarkan hasil penelitian ini dapat diambil beberapa simpulan yaitu: sebagian besar pupuk kompos produksi Simantri mempunyai kualitas yang baik yaitu mengandung kadar N, P, K, C-organik yang sangat tinggi, dan $\mathrm{C} / \mathrm{N}$ rasio yang rendah. Sebanyak $(57,14 \%)$ pupuk kompos produksi Simantri telah memenuhi sebagian persyaratan kualitas pupuk kompos SNI- 


\section{A.A. NYOMAN SUPADMA. et al. Kajian Kualitas Beberapa Pupuk Kompos Produksi Simantri...}

2004, dan hanya $42,86 \%$ belum memenuhi syarat kualitas SNI-2004 yakni pada parameter $\mathrm{pH}$ dan kadar air kompos. Pupuk kompos Simantri yang belum sesuai dengan standar kualiats SNI-2004 adalah kompos Simantri Tegalinggah, Tabanan dan Guang, Gianyar (kadar air lebih >50\%), kompos Simantri Kukuh Marga Tabanan dan Guang Gianyar $(\mathrm{pH}<6,8), \quad$ kompos Simantri Budakeling, Sidemen dan Duda Selat Karangasem; Pejeng Klod Gianyar; Selanbawak dan Tegalinggah Tabanan; Yehembang Jembrana ( $\mathrm{pH}>7,49)$ (tidak sesuai SNI-2004).

\section{UCAPAN TERIMA KASIH}

Melalui kesempatan yang baik ini kami mengucapkan terimakasih kepada Rektor, Ketua LPPM dan Dekan Fakultas Pertanian Unud, yang telah membiayai penelitian ini melalui DIPA PNBP Unud tahun 2016, dengan Skim Hibah Unggulan Program Studi.

\section{DAFTAR PUSTAKA}

Badan Standarisasi Nasional (BSN). 2004. Spesifikasi Kompos dari Sampah Organik Domestik. Jakarta. $26 \mathrm{~h}$.

Harada Y. 1990. Composting and Application of Animal Waste. ASPAC. Food and Fertilizer Technology Center. Extension Bulletin No $311: 20$ - 31 .

Isroi dan N. Yuliarti. 2009. Kompos. Penerbit Andi, Yogyakarta. $37 \mathrm{~h}$.

Murbandono, L. 2009. Membuat Kompos. Penebar Swadaya, Jakarta. $36 \mathrm{~h}$.

Novizan, 2005. Petunjuk Pemupukan Yang Efektif. Agromedia Pustaka, Jakarta. $34 \mathrm{~h}$.

Outerbridge,T.B. 1991. Limbah Padat di Indonesia. Yayasan Obor Indonesia. Jakarta. $31 \mathrm{~h}$.
Simanungkalit, R.D.M., Suriadikarta, D.A., Saraswati, R., Setyorini, D dan W. Hartatik., 2006. Pupuk Organik dan Pupuk Hayati. Balai Besar Penelitian dan Pengembangan Sumberdaya Lahan Pertanian. Bogor. http://balittanah.litbang.deptan.go.id/ Diakses tanggal 4 Februari 2015. 36 h. Suriadikarta, A.D., D. Setyorini \& W. Hartatik.2006. Petunjuk Teknis Uji Mutu dan Efektivitas Alternatif Anorganik \& Baku Mutu Pupuk Organik. Balai Penelitian Tanah, Puslitbangtanah Badan Penelitian dan Pengembangan Pertanian. Bogor.21 h.

Sugito, Y. 2005. Sistem Pertanian Berkelanjutan di Indonesia, Potensi dan Kendalanya. Bagpro PKSDM Ditjen Dikti Depdiknas kerjasama dengan Fakultas Pertanian Universitas Brawijaya, Malang. $23 \mathrm{~h}$.

Sutedjo, M.M.,A.G. Kartasapoetra, dan Rd. S. Sastroatmodjo. 1996. Mikrobiologi Tanah. PT. Rhineka Cipta Pemupukan Cetakan ke 6 Penerbit PT Rineka Cipta. Jakarta. Hal 56-57

Stofella, P.J \& Brian A. Khan, 2001. Compost Utilization in Holticultural Croping Systems. Lewis Publishers. USA. $17 \mathrm{~h}$.

Syekhfani. 2005. Peranan Bahan Organik Dalam Mempertahankan Kesuburan Tanah. Bagpro PKSDM Ditjen Dikti Depdiknas kerjasama dengan Fakultas Pertanian Universitas Brawijaya, Malang. $9 \mathrm{~h}$.

Tan, K. H. Dasar-Dasar Kimia Tanah. Gajah Mada University Press. Yogyakarta. $295 \mathrm{~h}$.

Tantri, T.P.T.N, Supadma, A.A.N., D.W.M. Arthagama. 2016. Uji Kualitas Beberapa Pupuk Kompos yang Beredar di Kota Denpasar. E-J. Agroekoteknologi Tropika. Vol.5, No. 1. Hal. 52-62. 